\title{
Starch-chitosan hydrogels prepared by reductive alkylation cross-linking
}

\author{
E. T. BARAN ${ }^{1,2 *}$, J. F. MANO ${ }^{1,2}$, R. L. REIS ${ }^{1,2}$ \\ ${ }^{1} 3 B^{\prime}$ 's Research Group-Biomaterials, Biodegradables and Biomimetics, University of Minho, \\ Campus de Gualtar, 4710-057, Braga, Portugal \\ ${ }^{2}$ Department of Polymer Engineering, University of Minho, Campus de Azurém, 4800-058, \\ Guimarães, Portugal \\ E-mail: turker.baran@dep.uminho.pt
}

\begin{abstract}
Starch-chitosan hydrogels were produced by oxidation of soluble starch to produce polyaldehyde and subsequently cross-linked with chitosan via reductive alkylation. The swelling ratio of starch-chitosan membranes was increased gradually with increasing starch ratio, but it was always lower than the native chitosan. In dry state, starch-chitosan membranes with low starch ratio $(0.16,0.38)$ showed similar tensile strength values to those of native chitosan while these values decreased with increasing starch ratios (0.73-1.36). Membranes in physiological buffer solution (PBS) gave a tensile modulus between 2.8 and $1.0 \mathrm{MPa}$, decreasing with increasing starch ratio $\left(0.16-1.36\left(W_{\text {starch }} / W_{\text {chitosan }}\right)\right)$. When the membranes were incubated in PBS only, a moderate weight loss was observed for the first two weeks. Original weights of low starch weight ratio membranes (0-0.38) were at near $85 \%$, while high ratio samples (0.73-1.55) were kept around $70 \%$ after three months. However, for the membranes incubated in $\alpha$-amylase solution, very fast weight loss was observed. For low starch ratio membranes $(0.16,0.38,0.73)$, the residual original weights were measured to be $11 \%, 6 \%, 20 \%$, while for high ratio membranes (1.04 and 1.36 ) these were $45 \%$ and $30 \%$, respectively, after two months of enzyme incubation. Scanning electron microscopy analysis of $\alpha$-amylase degraded membranes exhibited rough surface morphology.
\end{abstract}

\section{(C) 2004 Kluwer Academic Publishers}

\section{Introduction}

Biodegradable materials are needed for a range of biomedical applications. Depending on the application, these materials should disclose a variety of degradation kinetics that leads always to non-cytotoxic degradation products. As well as degradability and non-toxicity, mechanical properties of biomaterials are also important: for example, materials used, as surgical stent, catheter materials, and hydroactive dressing materials require adequate mechanical performances.

Chitosan has been proved and regarded to be biodegradable, non-cytotoxic and having some interesting biological activities [1]. Chitosan is the Ndeacteylated derivative of chitin, one of the most abundant polysaccharides found in nature [2]. Some of the recent studies, however, are indicating that chitosan, with higher than $60 \%$ deacetylation degree showing less degradation and it is not easily resorbable in vivo [3].

Starch, an agricultural biodegradable biopolymer is being increasingly more attractive because of its renewability, biodegradability, and low cost. Starch-based polymers have recently been proposed as having great potential for application in biomedical field as implant materials, drug delivery systems, and tissue engineering scaffolds $[4,5]$. In order to use in temporary medical applications, such as temporary hard tissue replacement, bone fracture fixation, and bone tissue scaffold, blends of starch with ethylene-vinyl alcohol copolymer (SEVA), acetate (SCA), and poly(caprolactone) (SPCL) were proposed [6-8].

For giving structural integrity to materials made from hydrated polymers, a cross-linking process is needed. It is desirable to use a cross-linking agent that is not only suitable for being applied in cross-linking of chitosan, but that is also of low toxicity and capable of forming stable and biocompatible cross-linked products. The most common cross-linkers used for cross-linking chitosan are gluteraldehyde [9] and formaldehyde [10], regarded as quite toxic chemicals. In order to eliminate toxicity problems, biological macromolecules and small molecules may be used as non-toxic alternatives for cross-linking. A natural cross-linking agent, genipin, was used to cross-link a chitosan hydrogel [11]. Chitosan was cross-linked by reductive alkylation with the polyaldehyde prepared from periodate oxidation of $\beta$ cyclodextrin, a multifunctional system [12]. Similarly, an alternative to the use of non-cytotoxic cross-linkers oxidised glycogen produced by periodate oxidation was

*Author to whom all correspondence should be addressed. 


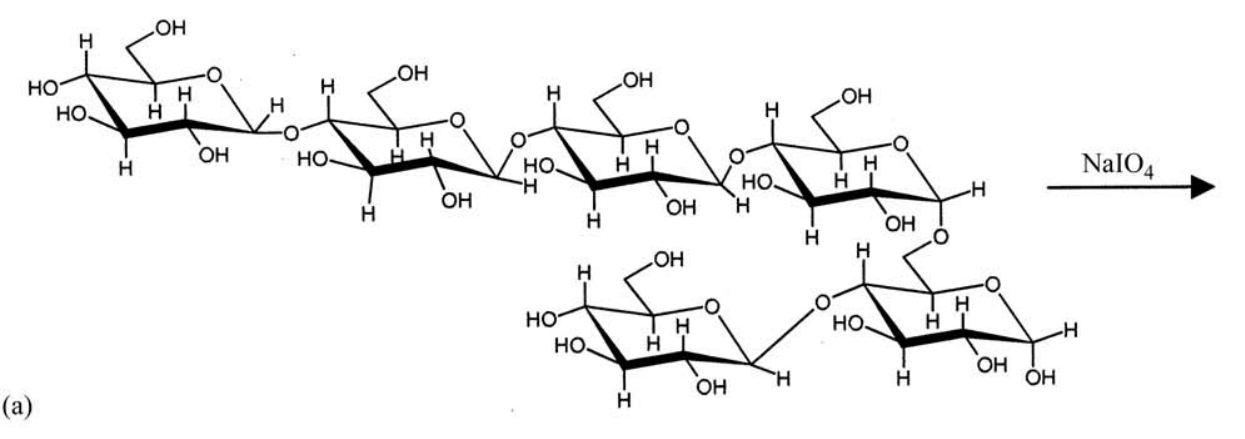

Starch

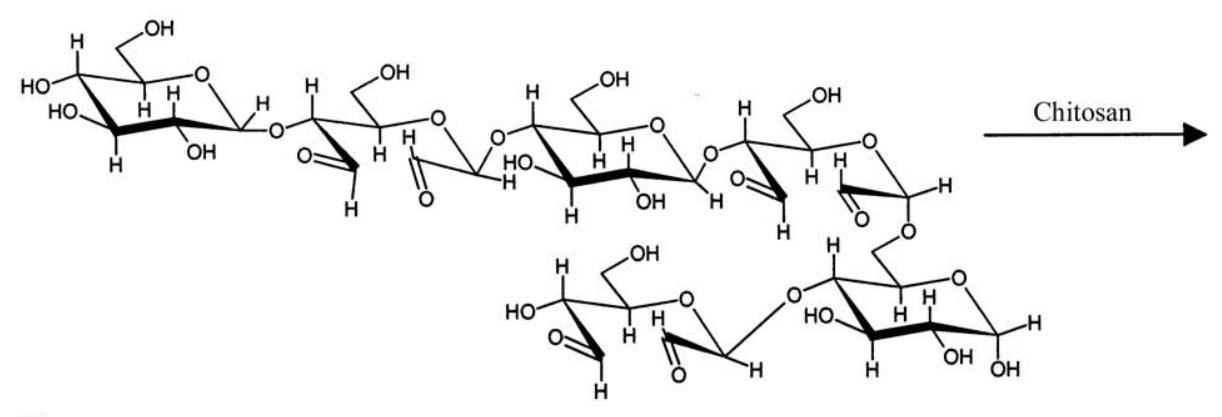

(b)

Oxidized starch

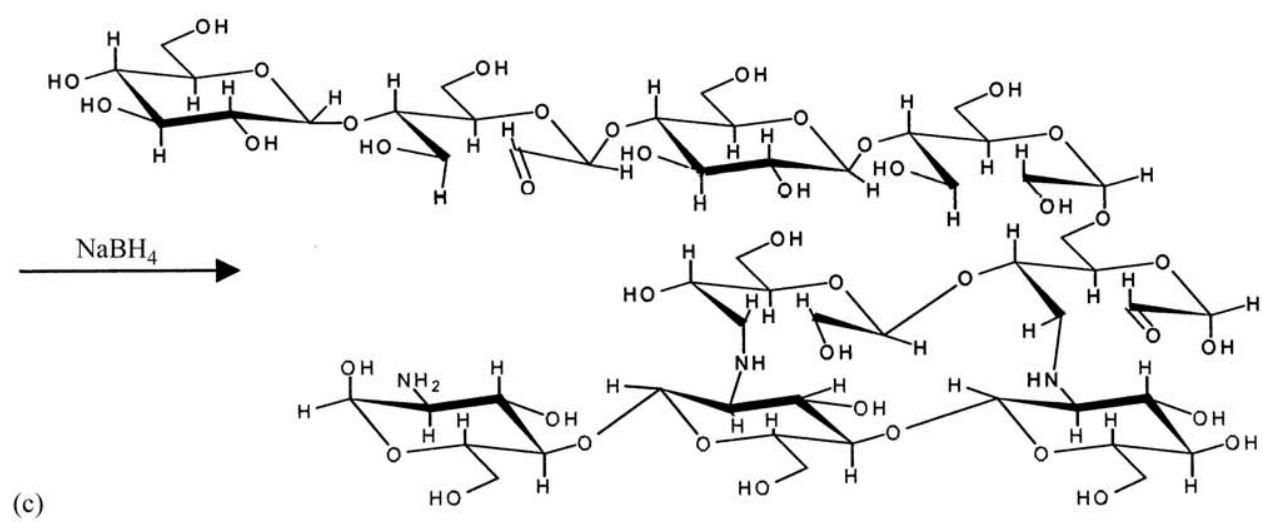

Starch-chitosan conjugate

Figure 1 Reaction of starch with chitosan after oxidation (a), imine conjugation (b), and reduction with $\mathrm{NaBH}_{4}(\mathrm{c})$.

used for the preparation of collagen films [13]. Dialdehyde bearing glucose molecule obtained by periodate oxidation was also studied as a possible natural cross-linker for chitosan [14].

Natural polysaccharides with free aldehyde groups such as oxidised cellulose, carboxymethylcellulose, and chondroitin sulphate, have been investigated by several investigators for possible medical applications together with chitosan [15-20].

In this study, soluble starch was oxidised by sodium iodate, for generation of polyaldehyde, and reacted with chitosan in aqueous solution via reductive alkylation process. Conjugation between primary amino of chitosan and aldehyde group of starch was stabilised by sodium borohydride reduction (Fig. 1). Characterisation of this new biomaterial, i.e. of starch-chitosan hydrogels with different weight ratios, was performed by means of mechanical tests and degradation studies in aqueous solutions.

In most biomedical applications, membranes are in direct contact with living tissues. Therefore, besides the usual mechanical characterisation carried out in the dry state, new systems should also be subjected to test routines that allows for the evaluation of their mechanical performance in more realistic conditions. In this work, the usual mechanical parameters of the developed materials were also characterised while the membranes were immersed in a physiological simulated solution that is when they are in the swollen state.

\section{Materials and methods}

Chitosan (deacetylation degree $87 \%$ ), acetic acid, sodium hydroxide, and sodium periodate were obtained from 
T A B L E I Composition of starch-chitosan membranes prepared for $25 \mathrm{~cm}^{2}$ Petri dishes

\begin{tabular}{lcl}
\hline $\begin{array}{l}\text { Starch-chitosan } \\
\text { weight ratio } \\
\left(W_{\text {starch }} / W_{\text {chitosan }}\right)\end{array}$ & $\begin{array}{l}\text { Oxidised starch } \\
(16.32 \mathrm{mg} / \mathrm{ml})(\mathrm{ml})\end{array}$ & $\begin{array}{l}\text { Chitosan } \\
(1 \%)(\mathrm{ml})\end{array}$ \\
\hline 0.16 & & \\
0.38 & 1.96 & 20 \\
0.73 & 4.65 & 20 \\
1.04 & 8.94 & 20 \\
1.36 & 12.74 & 20 \\
0.0 (chitosan membrane) & 16.66 & 20 \\
\hline
\end{tabular}

Sigma Chemical Co. (St Louis, USA). Soluble starch from potato origin was obtained from ATO (Wageningen, The Netherlands). $\alpha$-Amylase (EC 3.2.1.1) from Bacillus amyloliquefaciens was gently supplied by Genencor International, Inc. (Rochester, NY, USA). All the other chemicals used were of analytical grade.

\subsection{Preparation of oxidised starch}

Oxidation of soluble starch was performed according to the procedure described by Hermanson [21]. Briefly, soluble starch dissolved in distilled water $(20 \mathrm{mg} / \mathrm{ml})$ and then $0.125 \mathrm{ml}$ sodium iodate $\left(\mathrm{NaIO}_{4}\right)$ solution $(10 \mathrm{mg} / \mathrm{ml})$ was added for each $\mathrm{ml}$ starch solution in a light-protected glass vessel. Reaction was proceeded $30 \mathrm{~min}$ at RT with occasional shaking. In order to quench the reaction, $0.1 \mathrm{ml}$ of glycerin/ml of reaction medium was added and mixed $10 \mathrm{~min}$ at least before blending with chitosan solution.

\subsection{Preparation of starch-chitosan membranes}

Different amounts of oxidised starch were mixed with fixed amount of chitosan $(20 \mathrm{ml}, 1 \%(\mathrm{w} / \mathrm{v}))$ to prepare different weight ratio samples (Table I). Mixtures were casted into square plastic Petri plates $\left(25 \mathrm{~cm}^{2}\right)$. They were subsequently allowed to dry for several days at room temperature. After drying, carbonate buffer $(0.5 \mathrm{M}$, $\mathrm{pH}$ 8.5) was poured over starch-chitosan membranes inside Petri dishes and incubated for $3 \mathrm{~h}$ so that the conjugation between reactive aldehyde group of starch and primary amino group of chitosan can take place. Subsequently, membranes were washed several times with distilled water and they were incubated with aqueous sodium borohydride $\left(\mathrm{NaBH}_{4}\right)(0.05 \%)$ solution for $1 \mathrm{~h}$ to reduce excess non-cross-linked aldehyde groups and to stabilise imine conjugation between starch and chitosan. Finally, after washing several times with distilled water, membranes were allowed to dry on the same Petri dishes at room temperature.

\subsection{Swelling test}

The swelling ratios of swollen membranes were measured after reaching equilibration point (almost $3 \mathrm{~h}$ ) where no change in weight of samples was observed. The swelling ratios were calculated according to the following equation:

$$
\% \mathrm{~S}=\left(m_{\mathrm{w}}-m_{\mathrm{i}}\right) / m_{\mathrm{i}} \times 100
$$

where $\% \mathrm{~S}$ is the percentage of swelling, $m_{\mathrm{i}}$ and $m_{\mathrm{w}}$ is the weight of the samples before immersion and after equilibration period in physiological buffer solution (PBS), respectively.

\subsection{Mechanical test}

The stress-strain test of starch-chitosan membranes (membrane strips with $5 \mathrm{~mm}$ in width) in dry state were performed with Instron Universal Mechanical Tensile Machine at room temperature using a crosshead speed of $1.0 \mathrm{~mm} / \mathrm{min}$ and $40 \mathrm{~mm}$ grip distance. The results presented were the mean values of five independent measurements.

The stress-strain experiments in wet conditions were carried out in a DMA7e Perkin-Elmer apparatus, using the tensile mode, where a cylindrical metallic vessel with $0.5 \mathrm{~mm}$ wall thickness was fitted in the furnace of the equipment, taking the advantage of the vertical assembling of the apparatus pieces (furnace, probe tip, etc.). The outside diameter of the cylindrical vessel was as much as possible close to the inner-side diameter of the furnace cavity, in order to enhance the thermal contact between the furnace and the bath. The vessel was filled with PBS (0.154 M NaCl aqueous solution at $\mathrm{pH}$ 7.4). The calibration of the force of the apparatus was performed using a $50 \mathrm{mg}$ weight, with the probe tip immersed, which took into account the impulsion effect of the solution. The equipment used is a force-controlled apparatus; thus experiments were performed under constant stress rate, in this case $0.5 \mathrm{MP} \mathrm{min}^{-1}$. A small load was applied prior to the experiments $(20 \mathrm{kPa})$ to maintain the samples tight.

\subsection{In vitro degradation study}

Membranes (100 mg dry weight) with different weight ratios were put into Falcon tubes containing $50 \mathrm{ml} \mathrm{PBS}$ with or without $\alpha$-amylase $\left(\mathrm{pH} 7.4,37^{\circ} \mathrm{C}, 720 \mathrm{IU} / \mathrm{ml}\right)$. At predetermined time points, membranes were collected and excess buffer was removed from the surface by using tissue paper. Samples were weighted by using an analytical balance with $\pm 0.1 \mathrm{mg}$ accuracy. After the equilibration time ( $3 \mathrm{~h}$ ) of swelling in PBS, the measured weights of samples were considered as original weights $(100 \%)$. For the starch-chitosan membranes that were incubated in the presence of $\alpha$-amylase, the old solutions were changed with fresh enzyme solution in two weeks intervals.

\subsection{SEM surface investigation of $\alpha$-amylase degradation of starch-chitosan membranes}

The starch-chitosan membranes with $0.38\left(W_{\text {starch }} /\right.$ $\left.W_{\text {chitosan }}\right)$ ratios were placed in PBS with $\alpha$-amylase as described in Section 2.7. At different time points, membranes were taken out and washed extensively with distilled water. After drying membranes at room temperature, the surface of samples was coated with an ultrathin layer of gold under vacuum. The surface morphology of samples was analysed by scanning electron microscopy (Leica Cambridge S360 microscope). 


\section{Results and discussion}

\subsection{Swelling tests}

Swelling ratio of starch-chitosan membranes at PBS ( $\mathrm{pH}$ 7.4) were increased gradually with increasing starch ratio (Fig. 2). This can be explained by increased amount of starch cross-linked with fixed amount of chitosan. Since only limited proportion of aldehyde groups can be cross-linked with amino groups of chitosan, hydroxyls derived from reduced aldehydes by $\mathrm{NaBH}_{4}$ reduction as well as unreacted starch hydroxyls may hydrate polymer more by increased amount. The swelling ratio of low starch ratio polymer $(0.16(\mathrm{w} / \mathrm{w}))$ indicated lowest swelling ratio around $110 \%$, much lower than the native chitosan that gave highest value around $180 \%$ (Fig. 2). By using low amount of oxidised starch, crosslinking of chitosan can be achieved quite effectively without using toxic cross-linkers such as formaldehyde and gluteraldehyde.

\subsection{Mechanical tests}

In dry state, starch-chitosan membranes with low starch ratio $(0.16,0.38)$ showed similar tensile strength values as native chitosan as seen from Table II. These values were decreased suddenly with increasing starch ratio (0.73-1.36). With increasing starch ratio the strain values were decreased, showing an increase in rigidity of membranes for higher cross-linking levels. As a conclusion, at low starch ratio the strength and modulus of starch-chitosan is comparable with native chitosan. At high ratio, the strength and flexibility of membranes were affected adversely because of high cross-linking level.

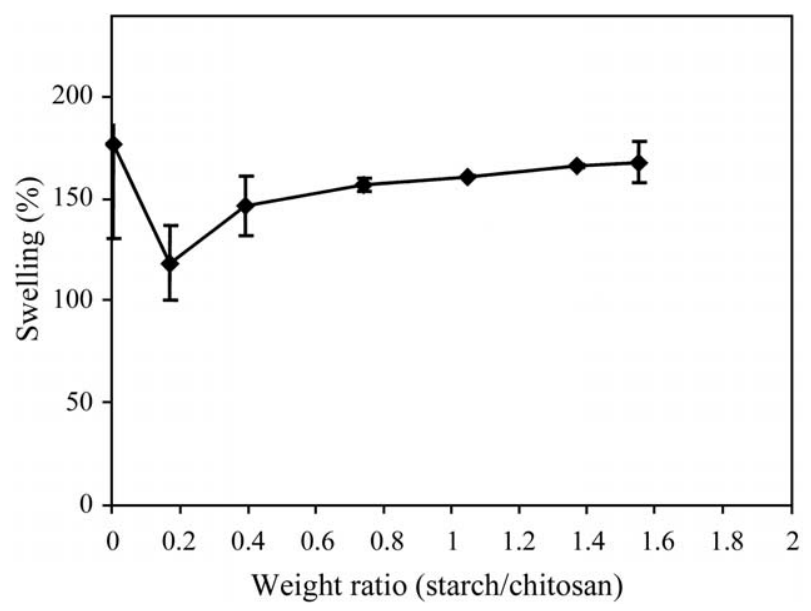

Figure 2 Swelling behaviour of starch-chitosan membranes with different weight ratio in PBS ( $\mathrm{pH} 7.4)$.

TA B LE II Stress, modulus, and strain average values of dry starch-chitosan membranes with different weight ratio $(n=5$, temp.: $22^{\circ} \mathrm{C}$, humidity: 56 )

\begin{tabular}{llll}
\hline $\begin{array}{l}\text { Starch-chitosan weight } \\
\text { ratio }\left(W_{\text {starch }} / W_{\text {chitosan }}\right)\end{array}$ & $\begin{array}{l}\text { Stress max } \\
\text { load }(\mathrm{MPa})\end{array}$ & $\begin{array}{l}\text { Modulus } \\
\left(E_{1} \%\right)(\mathrm{MPa})\end{array}$ & $\begin{array}{l}\text { Maximum } \\
\text { strain }(\%)\end{array}$ \\
\hline 0.166 & 54.5 & 2095.0 & 4.1 \\
0.38 & 50.4 & 1872.0 & 3.6 \\
0.73 & 22.4 & 927.4 & 2.0 \\
1.04 & 14.8 & - & 1.61 \\
1.36 & 28.9 & 2201.0 & 1.8 \\
0 (chitosan membrane) & 53.7 & 2070.0 & 8.4 \\
\hline
\end{tabular}

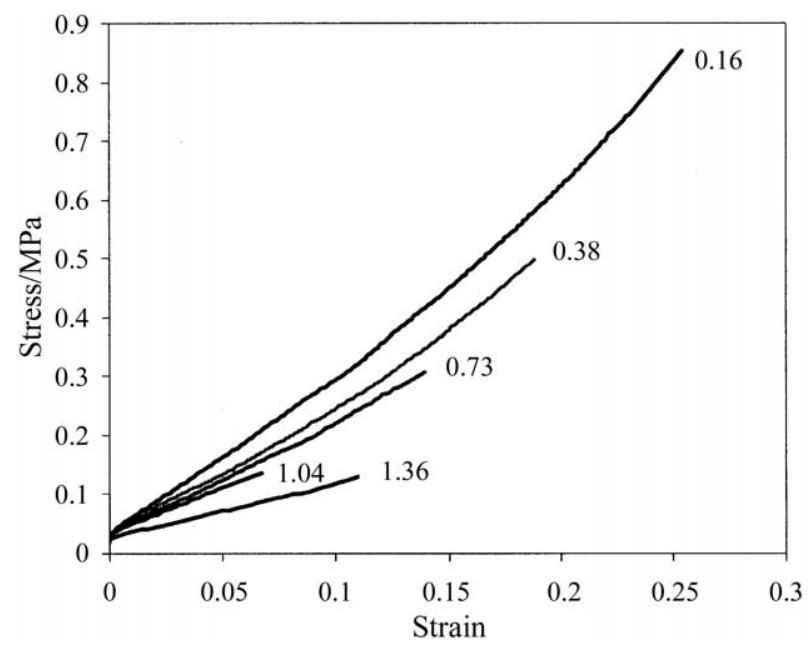

Figure 3 Stress-strain curves obtained in the developed chitosan/starch blends under wet conditions. The used stress rate was $0.5 \mathrm{MPa} \mathrm{min}^{-1}$.

Fig. 3 shows the stress-strain curves in wet conditions obtained from the studied formulations. Mainly for starch/chitosan weight ratio at 0.16 , a clear curvature is detected in the plots, indicating, e.g. that for higher stresses the change in the strain is getting smaller, i.e. the materials are getting stiffer during deformation. The general shape of the curves is quite similar to the ones observed in elastomers [22]. This is due to the high elastic character of the membranes, caused by the existence of cross-links and the mobility of the macromolecular segments; the last effect is mainly caused by the plasticisation effect of the solution on the materials that allows for a significant enhancement of conformational freedom. The results in Fig. 3 suggest that the stiffness, the strength, and the maximum strain decreases as the starch content increases; an exception is the higher strain at break for weight ratio at 1.36 with respect to ratio at 1.04 . These findings are confirmed in Fig. 4, where the modulus (at 2\%), the stress at break and the maximum strain are plotted for all formulations.

Chitosan films blended with poly(ethylene glycol) (PEG) produced to obtain better mechanical properties showed similar results [23]. PEG was found not to alter the strength significantly and even deteriorating at high PEG ratio (maximum stresses between 4 and 7 MPa with $1: 2$ and $4: 1$ chitosan-to-PEG at dry state). Chitosan strips (to be used as surgical stent) in swollen state (immersed in PBS) yielded values as the maximum stress at $0.59 \mathrm{MPa}$ with a modulus of $0.76 \mathrm{MPa}$ [24]. Modulus obtained with swollen poly(vinylalcohol)/chitosan lactate membranes [25] showed decreasing in value 2.0$0.1 \mathrm{MPa}$ with increasing chitosan lactate-to-PVA ratio (0.2-1.0). As compared with above values and several other blends in literature [26-28] several chitosan blends (there is no chemical linkage), our results gave moderate strength values in swollen state.

\subsection{In vitro degradation tests}

In PBS solution, starch-chitosan membranes showed a significant weight loss on the initial two weeks then showed less significant weight loss until third month. This must be the result of leaching of loosely crosslinked polymeric chains (starch and chitosan). Original 


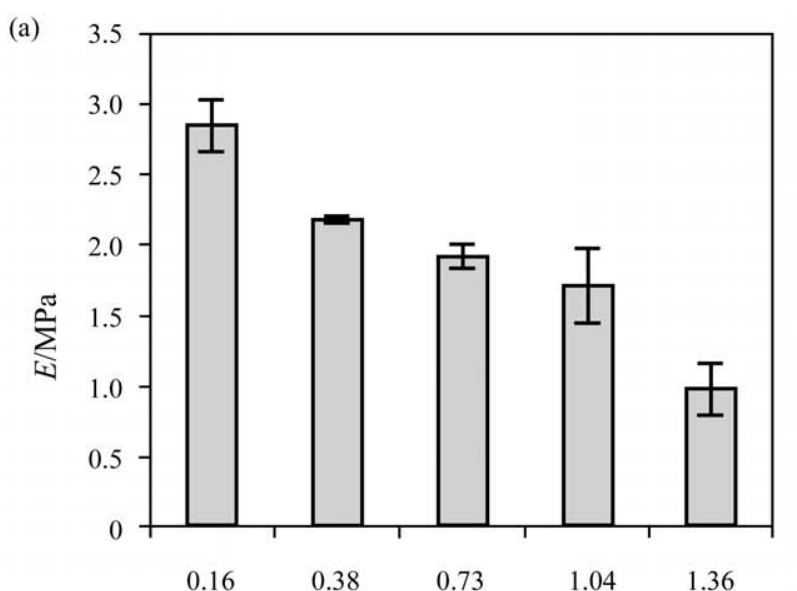

Weight ratio (starch/chitosan)

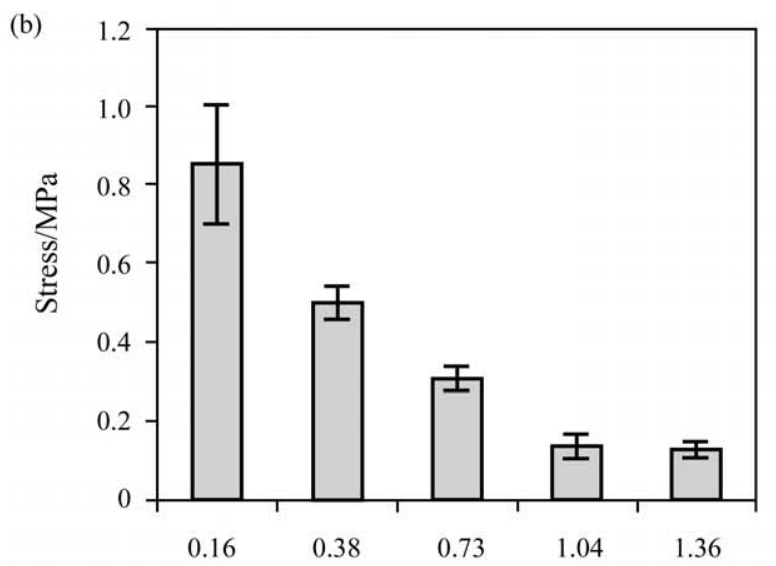

Weight ratio (starch/chitosan)

(c)

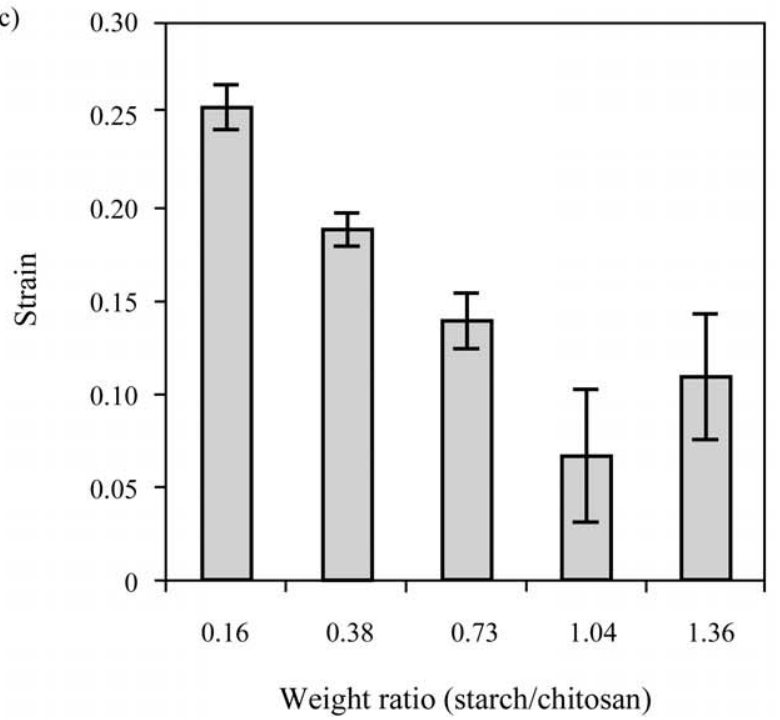

Figure 4 (a) Tensile modulus (secant modulus at 2\%); (b) stress at break and (c) strain at break of the studied materials in wet conditions, obtained from the stress-strain experiments as shown in Fig. 3.

weight of low starch ratio membranes (0-0.38 $\left(W_{\text {starch }} / W_{\text {chitosan }}\right)$ ) were found at near $85 \%$ while high starch weight ratio samples $(0.73-1.55)$ were found to be around $70 \%$ after three months (Fig. 5). As a result, it is clear that high starch ratio polymers loose more weight in PBS then compared with low starch ratio polymers.

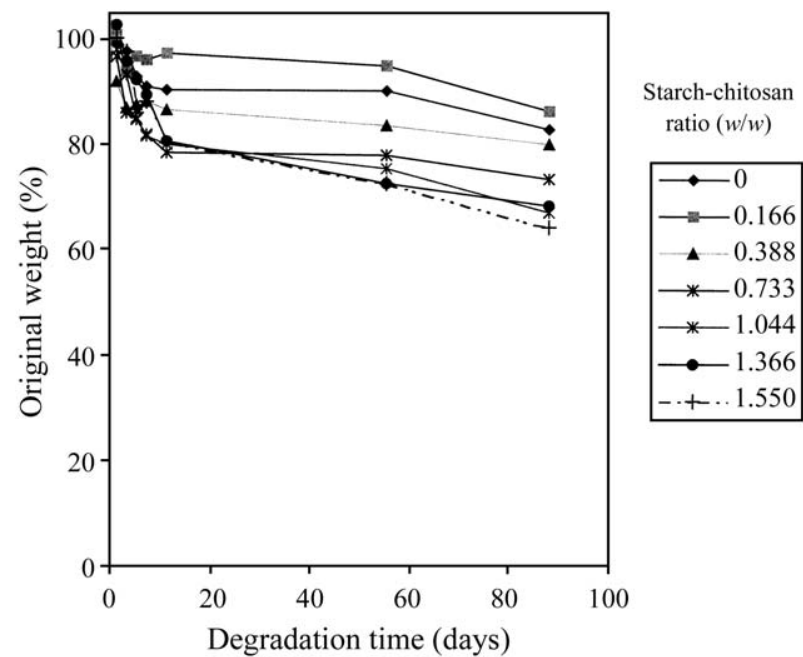

Figure 5 Weight loss profiles of starch-chitosan membranes with different weight ratio at $37^{\circ} \mathrm{C}$ in $\mathrm{PBS}$ ( $\mathrm{pH} 7.4$ ).

For the membranes incubated in $\alpha$-amylase solution, however, very fast degradation was observed in contrast to PBS incubation test. A lag period with slight increase in swelling was observed for two weeks probably only chain cleavage of cross-linked starch molecule was operated by $\alpha$-amylase without leaching of molecules into solution (Fig. 6). Low weight ratio membranes $\left(0.16,0.38\left(W_{\text {starch }} / W_{\text {chitosan }}\right)\right)$ were seen degraded fast after the lag period. After two months, the original weight of the low starch ratio membranes was found at 11 and $6.0 \%$, respectively. High starch ratio membranes $\left(0.73,1.04,1.36\left(W_{\text {starch }} / W_{\text {chitosan }}\right)\right)$, however, these values were at 20,45 , and $30.8 \%$, respectively. High starch ratio membranes can be expected to degrade fast by $\alpha$-amylase. However, in our case high starch ratio membranes were degraded slowly. These results can be attributed to decreased surface/volume ratio by means of swelling of membranes with increased starch amount. In that case, enzymatic degradation of conjugate would depend on surface availability of the material. Another reason may be the saturation of $\alpha$-amylase catalytic sites by increased amount of starch, in turn, slows down the degradation rate.

A suprising result obtained with this study is the degradation of starch-chitosan membranes beyond their starch contents. Since $\alpha$-amylase cannot degrade chitosan, this must be the result of leaching of chitosan

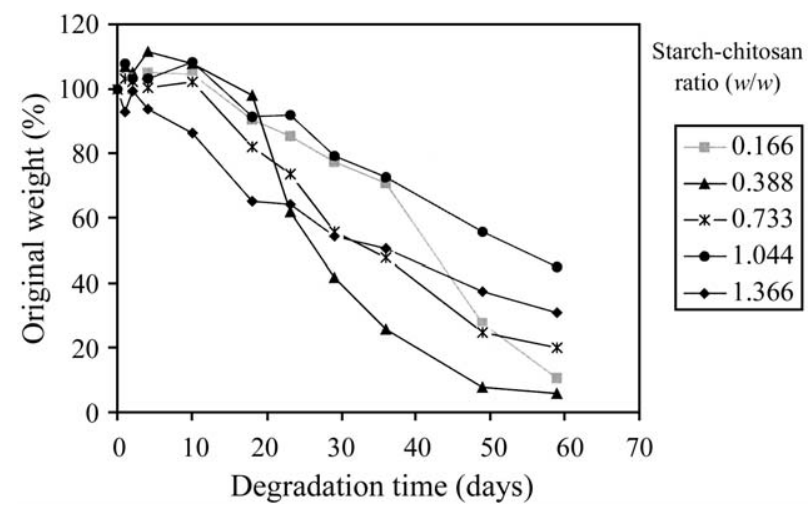

Figure 6 Degradation of starch-chitosan membranes with different weight ratio in the presence of $\alpha$-amylase solution (in $\mathrm{PBS}, 37^{\circ} \mathrm{C}$, $727.5 \mathrm{U} / \mathrm{ml}$ enzyme activity). 


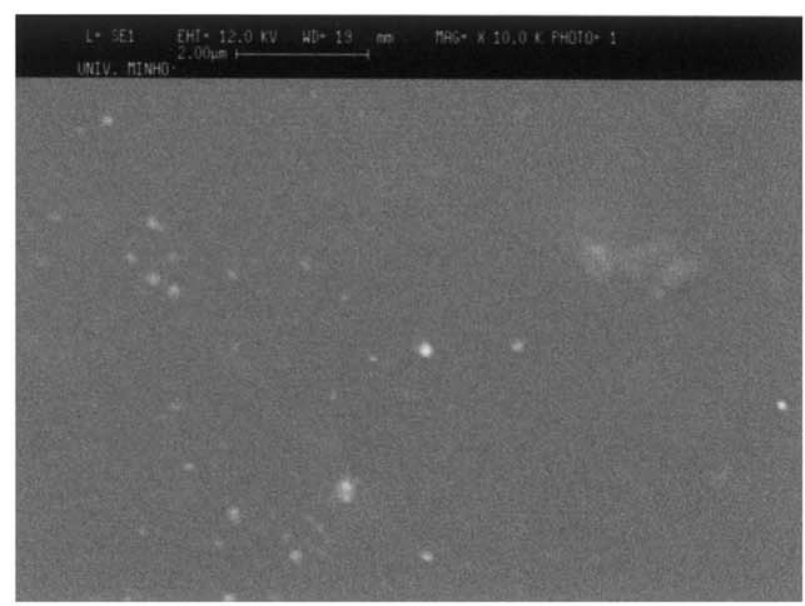

(a)

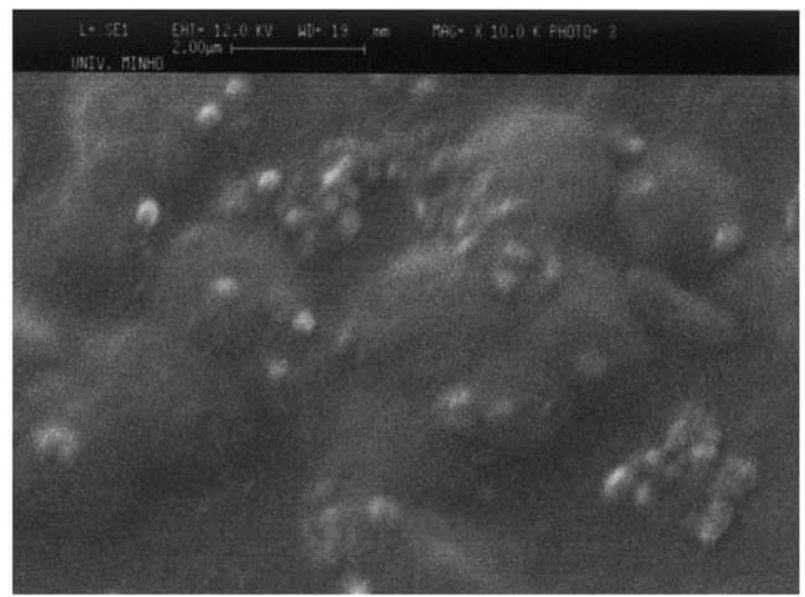

(c)

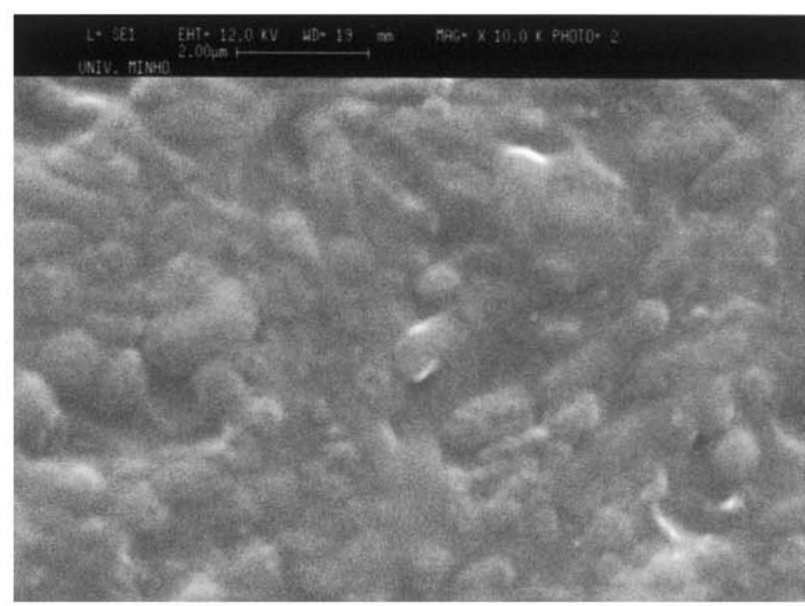

(b)

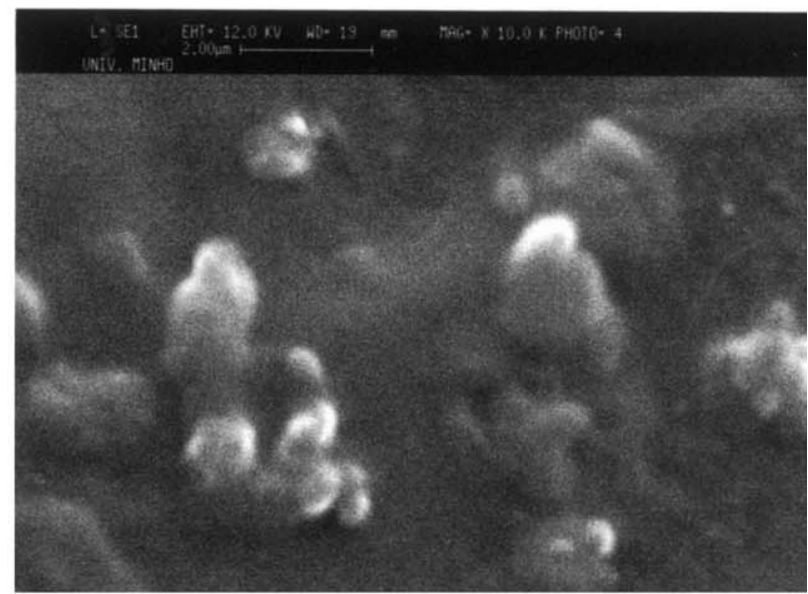

(d)

Figure 7 SEM microphotographs of starch-chitosan membranes incubated in the presence of $\alpha$-amylase (in PBS, $37^{\circ} \mathrm{C},(\mathrm{a}) 0$ day, (b) 11 day (c) 18 day, and (d) 26 day.

molecules cross-linked between networks of degrading starch molecules by $\alpha$-amylase. In a study by Tomihata and Ikada [3], the authors indicated that the chitosan films that were more than $73 \%$ deacetylated showed very slow or no degradation in vivo. Since human plasma contains appreciable amylase activity, starch modification may improve the rate of degradation of chitosan containing materials under in vivo conditions. Furthermore, the rate of biodegradation of these novel biomaterials in implant site can be customised by changing the starch to chitosan ratios.

\subsection{SEM surface investigation of $\alpha$-amylase degradation of starch-chitosan membranes}

Starch-chitosan membranes with $0.38\left(W_{\text {starch }} / W_{\text {chitosan }}\right)$ ratios were incubated in $\alpha$-amylase and their surface morphologhy was investigated by SEM at different time points. The roughness of surfaces was seen increased with the time of enzyme incubation. At the end of the 26 days of incubation, membranes were discovered with very rough topology and covered with micron-sized spikes all over the surface (Fig. 7). The control membranes (incubated in PBS without $\alpha$-amylase) showed quite smooth surfaces, although at the end of the 26 days of incubation, the surface was seen to be slightly granular (not shown in figures). The absence of holes or pores inside the material suggest that the degradation of membranes by $\alpha$-amylase is taking place at the surface only. This result supports our abovementioned proposal suggested for decreased weight loss, observed for high starch ratio membranes: increase in swelling of membranes due to increased starch content must decrease the area/volume ratio, thereby, the degradation rate.

\section{Conclusions}

Soluble starch was aldehyde generated by periodate oxidation and subsequently reacted with chitosan by reductive alkylation procedure in different weight ratios. The swelling degree of membranes were increased directly with increasing starch ratio except for the lowest ratio $\left(0.16\left(W_{\text {starch }} / W_{\text {chitosan }}\right)\right)$, which gave the lowest swelling rate at about $110 \%$. At low starch ratios $(0.16,0.38)$, the tensile strength values of dry starchchitosan membranes were close to that of native chitosan. At higher starch ratios (0.73-1.36), however, the tensile strengths of membranes were affected adversely and flexibility was decreased. The stress-strain curves of membranes in wet condition showed elastic character for low starch ratio (0.16) membranes, caused by the existence of cross-links and the mobility of the macromolecular segments. The stiffness, the strength, and the maximum strain were found to be decreased as 
the starch content increases. Starch-chitosan membranes preserved their original weights around $85 \%$ for low ratios $(0-0.38)$ after three months of incubation in PBS at $37^{\circ} \mathrm{C}$. For high starch ratios $(0.73-1.36)$, these values were found to be around $70 \%$. In the presence of $\alpha$ amylase, low starch ratio $(0.16,0.38)$ membranes showed fast degradation with protection of 11 and $6 \%$ of their original weights, respectively. For high starch ratio $(0.73,1.04,1.36)$ membranes, however, these values were detected as 20,45 , and $30.8 \%$, respectively. SEM images of starch-chitosan membranes in the presence of $\alpha$-amylase at $37^{\circ} \mathrm{C}$ showed extensive rough surface pattern formation, increasing with the duration of incubation.

\section{Acknowledgments}

E. T. Baran thanks the Portuguese Foundation for Science and Technology for providing him with a PostDoc Scholarship (BDP/10874/2002). This work was partially supported by FCT Foundation for Science and Technology, through funds from the POCTI and/or FEDER programs.

\section{References}

1. T. CHANDy and C. P. Sharma, Biomater. Artif. Cells Artif. Organs 18 (1990) 1.

2. T. D. RAthKe and S. M. hudson, J. Mater. Sci.: Rev. Macromol. Chem. Phys. C 35 (1994) 155.

3. K. TOMIHATA and Y. IKA DA, Biomaterials 18 (1997) 567.

4. A. P. MARQUES, R. L. REIS and J. HUNT, ibid. 23 (2002) 1471.

5. C. ELVIRA, J. F. MANO, J. SAN ROMAN and R. L. REIS, ibid. 23 (2002) 1955.

6. R. L. REIS, A. M. CUnhA and M. J. BeVIS, J. Polym. Adv. Tech. 7 (1996) 784.

7. R. L. REIS, S. C. MENDES, A. M. CUNHA and M. J. BEVIS, Polym. Int. 43 (1997) 347.

8. A. J. SAlgADo, M. E. GOMES, A. ChOU, O. P. COUTINHO, R. L. REIS and D. W. HUTMACHER, Mat. Sci.Eng. C 20 (2002) 27.
9. F. MI, Y. TAN, H. LIANG and H. SUNG, Biomaterials 23 (2002) 181.

10. P. HE, S. S. DAVIS and L. ILlu M, Int. J. Pharm. 187 (1999) 53.

11. H. W. SUNG, R. N. HUANG, L. L. HUANG, C. C. TSAI and C. T. CHIU, J. Biomed. Res. 4 (1998) 560.

12. V. CRESCENZI, G. PARADOSSI, P. DESIDERI, M. DENTINI, F. CAVAlieri, E. AMICI and R. LiS I, Polym. Gels Networks 5 (1997) 225.

13. C. F. ROUSSEAU and C. H. GAGNIEU, Biomaterials 23 (2002) 1503.

14. F. LI, W. G. LIU and K. D. YAO, ibid. 23 (2002) 343.

15. M. G. CASCONE, N. BARBANI, C. CRISTALLINI, P. GIUSTI, G. CIARDELli and L. LAZZERI, J. Biomater. Sci. Polym. Ed. 12 (2001) 267.

16. J. MULhBACHER, P. ISPAZ-SZABo, V. LENAERTS and M. A. MATEESCU, J. Contr. Release 76 (2001) 51.

17. S. T. LIM, G. P. MARTIN, D. J. BERRY and M. B. BROWN, ibid. 66 (2000) 281.

18. A. GANZA-GONZALEZ, S. ANGUIANO-IGEA, F. J. OTEROESPINAR and J. B. MENDEZ, Eur. J. Pharm. Biopharm. 48 (1999) 148.

19. G. PARAdossi, E. ChIESSi, F. CAVAlieri, D. MOSCONE and V. CRES KenZI, Polym. Gel Networks 5 (1997) 525.

20. T. EFRENFREUND-KLEINMAN, Z. GAZIT, D. GAZIT, T. AZZAM, J. GOLENSER and A. J. DOMB, Biomaterials 23 (2002) 4621.

21. G. T. HERMANSON, in "Bioconjugate Techniques" (Academic Press, 1996), p. 116.

22. L. H. SPERLING, in "Introduction to Physical Polymer Science", (Wiley, New York, 2001) 371.

23. M. ZHANG, X. H. LI, Y. D. GONG, N. M. ZHAO and X. F ZHANG, Biomaterials 23 (2002) 2641.

24. A. LAUTO, M. OHEBSHALOM, M. ESPosito, J. Mingin, P. S. LI, D. FELSEN, M. GOLDSTEIN and P. POPPAS, ibid. 22 (2001) 1869.

25. A. A. QUeIRoZ, H. G. FERRAZ, G. A. ABRAhAM, M. M FERNANDEZ, L. BRAVO and J. SAN ROMAN, J. Biomed. Mat. Res. 64A (2003) 147.

26. D. R. RUEDA, T. SECALLAND and R. K. BAYER, Carbohydr. Polym. 40 (1999) 49.

27. T. MUSLIM, M. MORIMOTO, H. SAIMOTO, Y. OKAMOTO, S MINAMI and Y. SHIGEMASA, ibid. 46 (2001) 323.

28. A. LAZARIDOU and C. G. BILIADERIS, ibid. 48 (2002) 179.

Received 5 September 2003

and accepted 10 February 2004 